2009-01-01

\title{
Transcriptional Regulation of Cholesterol 24-hydroxylase by Histone Deacetylase Inhibitors.
}

\author{
Marjan Shafaati \\ Karolinska Institute \\ Riona O'Driscoll \\ Technological University Dublin \\ Ingemar Bjorkhem \\ Karolinska Institute
}

See next page for additional authors

Follow this and additional works at: https://arrow.tudublin.ie/scschbioart

Part of the Biochemistry Commons, and the Molecular Biology Commons

\section{Recommended Citation}

Shafaati, M., O'Driscoll, R., Bjorkhem, I. and Meany, S. (2009) Transcriptional regulation of cholesterol 24-hydroxylase by histone deacetylase inhibitors.Biochemical and Biophysical Research

Communications, Volume 378, Issue 4, 23 January 2009, Pages 689-694. doi:10.1016/j.bbrc.2008.11.103

This Article is brought to you for free and open access by the School of Biological Sciences at ARROW@TU Dublin. It has been accepted for inclusion in Articles by an authorized administrator of ARROW@TU Dublin. For more information, please contact arrow.admin@tudublin.ie, aisling.coyne@tudublin.ie,gerard.connolly@tudublin.ie.

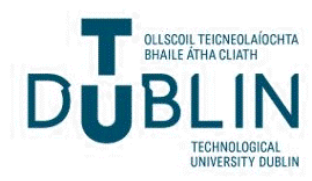




\section{Authors}

Marjan Shafaati, Riona O'Driscoll, Ingemar Bjorkhem, and Steve Meaney

This article is available at ARROW@TU Dublin: https://arrow.tudublin.ie/scschbioart/49 


\title{
Transcriptional regulation of cholesterol 24-hydroxylase by histone deacetylase inhibitors
}

\author{
Marjan Shafaati ${ }^{\mathrm{a}}$, Riona O’Driscoll ${ }^{\mathrm{a}}$, Ingemar Björkhem ${ }^{\mathrm{a}}$, Steve Meaney ${ }^{\mathrm{a}, \mathrm{b}, *}$ \\ a Division of Clinical Chemistry, Department of Laboratory Medicine, Karolinska University Hospital-Huddinge, Karolinska Institutet, Stockholm, Sweden \\ ${ }^{\mathrm{b}}$ School of Biological Sciences, Faculty of Science, Dublin Institute of Technology, Dublin 2, Ireland
}

\section{A R T I C L E I N F O}

\section{Article history:}

Received 12 November 2008

Available online 4 December 2008

\section{Keywords:}

24S-hydroxycholesterol

CYP46A1

CYP39A1

Epigentics

Histone deacetylase inhibitor

Oxysterol

Brain cholesterol

\begin{abstract}
A B S T R A C T
The mechanistic basis for the tissue specific expression of cholesterol elimination pathways is poorly understood. To gain additional insight into this phenomenon we considered it of interest to investigate if epigenetic mechanisms are involved in the regulation of the brain-specific enzyme cholesterol 24hydroxylase (CYP46A1), a key regulator of brain cholesterol elimination. We demonstrated a marked time-dependent derepression of the expression of CYP46A1, in response to treatment with the potent histone deacetylase (HDAC) inhibitor Trichostatin A. The pattern of expression of the genes in the genomic region surrounding CYP46A1 was found to be diametrically opposite in brain and liver. Intraperitoneal injection of HDAC inhibitors in mice led to a significant derepression of hepatic Cyp46a1 mRNA expression and tissue specific changes in Hmgcr and Cyp39a1 mRNA expression. These results are discussed in the context of the phenomenology of tissue specific cholesterol balance.
\end{abstract}

(c) 2008 Elsevier Inc. All rights reserved.
Although all nucleated cells are capable of cholesterol synthesis, their ability to do so varies over several orders of magnitude. In the adult state most organisms have established a certain level of tissue specialisation [1]. The rate of cholesterol synthesis and the cholesterol content of a given tissue are not necessarily directly related, e.g. the adult brain contains more than $25 \%$ of whole body cholesterol but turns over only $0.03 \%$ of its cholesterol content each day. This turnover is much lower than the developing brain [1] where cholesterol rich myelin is being formed. The slow turnover of brain cholesterol is in marked contrast to that in most other organs [1,2]. The mechanistic basis for these differences is unknown, although they are probably a result of the functional isolation of brain and blood cholesterol [3-5].

According to current concepts, the synthesis and elimination of cholesterol in the adult brain is compartmentalised-astroglial cells are believed to be responsible for the majority of synthesis in the adult brain while they contribute relatively little to brain elimination. The neuron specific cytochrome P450 cholesterol 24-hydroxylase (CYP46A1) is responsible for the elimination of about two thirds of the cholesterol synthesised by the brain [6,7]. Recently it was shown that deletion of this gene led to a reduction in the rate of brain cholesterol synthesis while the level of brain cholesterol was maintained [8]. Due to the importance of this

\footnotetext{
* Corresponding author. Present address: School of Biological Sciences, Faculty of Science, Dublin Institute of Technology, Dublin 2, Ireland.

E-mail address: steve.meaney@dit.ie (S. Meaney).
}

enzyme for brain cholesterol balance we have previously investigated its transcriptional regulation [9], with an expectation that a gene so important for brain cholesterol balance would be subject to complex mechanisms of regulation. Surprisingly we found the opposite-expression of CYP46A1 was insensitive to mechanisms known to regulate the key genes in cholesterol synthesis and elimination, HMGCR and CYP7A1, respectively. However, there are several examples in the literature indicating that CYP46A1 can be induced [10-12]. A recent study by Milagre et al. indicated that members of the SP1 family of transcription factors might regulate CYP46A1 [13].

We considered it of high importance to investigate if epigenetic mechanisms are involved in the control of the expression of CYP46A1. In this form of regulation, distinct patterns of gene expression are inherited by chromatin modifications, such as DNA and histone methylation, that do not involve changes in DNA [14]. Using a combination of in vitro and in vivo approaches we show that the expression of CYP46A1, as well as other cytochrome P450s involved in cholesterol homeostasis, are potently regulated by histone acetylation status.

\section{Materials and methods}

Materials. Trichostatin A was obtained from Sigma or from Invivogen. Valproate was from Apoteket $\mathrm{AB}$ (Stockholm, Sweden). Adult brain total RNA was from Clontech. Adult liver RNA was a generous gift from Dr. Eva Ellis. Cell culture reagents were from 
Invitrogen. Primers for PCR were from Cybergene $A B$ or assays on demand (Applied Biosystems, Carlsbad, CA).

Cell culture and treatment with Trichostatin A. Human SH-SY5Y neuroblastoma cells were cultured in DMEM containing $10 \%$ foetal calf serum, $1 \%$ Glutamax, $100 \mathrm{U} / \mathrm{ml}$ penicillin, and $100 \mu \mathrm{g} / \mathrm{ml}$ streptomycin (all from Invitrogen, Carlsbad, CA) in a humidified incubator at $5 \% \mathrm{CO}_{2}$. Cells were seeded into $35 \mathrm{~mm}$ dishes and allowed to recover overnight before any addition of reagent. In initial time course experiments cells were exposed to TSA at a final concentration of $0.5 \mu \mathrm{M}$. After $0,0.5,1,2,4,8$ and $24 \mathrm{~h}$ of incubation the medium was removed and cells were scraped into $1 \mathrm{~mL}$ of Trizol per dish (Invitrogen, Carlsbad, CA). Cell pellets in Trizol were frozen at $-80^{\circ} \mathrm{C}$ until required. Subsequently cells were seeded into six well plates, allowed to recover and exposed to $0.5 \mu \mathrm{M}$ TSA for $48 \mathrm{~h}$. Cells were harvested and stored as described above.

Animal Experiment I-chronic effects of valproate treatment. Six-week-old male C57/B6-J mice $(n=5)$ were injected intraperitoneally with $700 \mathrm{mg} / \mathrm{kg}$ Ergenyl (valproic acid) dissolved in physiological saline. Controls $(n=5)$ received an equal volume of vehicle. Injections were continued for five days and performed between 10 and $11 \mathrm{am}$. On day six the animals were stunned with $\mathrm{CO}_{2}$ and killed by cervical dislocation. The brain and liver were removed, weighed, snap frozen in liquid nitrogen and stored at $-80^{\circ} \mathrm{C}$ until required.

Animal Experiment II-acute effects of Trichostatin A treatment. C57/B6-J mice (as above) were injected intraperitoneally with 0 , 2,5 or $10 \mathrm{mg} / \mathrm{kg}$ of TSA dissolved in DMSO and diluted in physiological saline to a final DMSO concentration of $18 \%$. The total volume injected was $250 \mu \mathrm{L}$. Two hours after injection mice were stunned with $\mathrm{CO}_{2}$ and killed by cervical dislocation. The brain and liver were removed, weighed, snap frozen in liquid nitrogen and stored at $-80^{\circ} \mathrm{C}$ until required.

Animal Experiment III-chronic effects of Trichostatin A treatment. Male C57/B6-J mice $(n=5)$ were injected intraperitoneally with $2 \mathrm{mg} / \mathrm{kg}$ TSA as described above. Controls $(n=5)$ received an equal volume of vehicle. Injections were continued for nine days and performed between 7 and $8 \mathrm{am}$. On day nine, approximately three hours following the last injection, the mice were stunned with $\mathrm{CO}_{2}$ and killed by cervical dislocation. Brain and liver samples were collected and stored as described above.

Gene expression analysis. Total RNA was purified from cell or tissue samples using Trizol (Invitrogen, Carlsbad, CA). cDNA was synthesised from $2 \mu \mathrm{g}$ of total RNA using the High Capacity cDNA ReverseTranscription Kit (Applied Biosystems, Foster City, CA). Steady-state mRNA levels were estimated using either Taqman probes or SYBR green chemistries (primer sequences available on request). All assays were run on an ABI Prism 7000 Sequence Detection System (Applied Biosystems; Foster City, CA). Estimation of relative gene expression was performed using the comparative threshold cycle method, using cyclophilin A and hypoxanthineguanine phosphoribosyl transferase (HPRT) as endogenous controls for cell culture and tissue samples, respectively.

Long-range chromatin mapping. One microgram samples of human adult brain and liver total RNA were used as templates for first strand cDNA synthesis using Superscript III and random hexamers (both from Invitrogen, Carlsbad, CA). RT-qPCR was performed using the Power SYBR green kit and using HPRT as endogenous control (primers available on request). Expression levels were calculated according to the comparative threshold cycle method using liver as the reference tissue. The range of expression was calculated by solving the expression $2^{-\Delta \Delta C t+S}$, where $S$ is the sum of the squared standard deviations (SSD) for each gene in each tissue, which accounts for the variance in the expression of both HPRT and the target gene in each tissue.

Lipid extraction and analysis. Approximately $10 \mathrm{mg}$ of brain tissue was added to $1 \mathrm{~mL}$ homogenisation buffer ( $5 \mathrm{mM}$ EDTA,
$50 \mu \mathrm{g} / \mathrm{ml}$ BHT in phosphate-buffered saline, $\mathrm{pH}$ 7.4) in a glass tube and the tissue was disrupted using a polytron homogeniser. Three millilitres of chloroform:methanol $(2: 1, v: v)$ were added and the samples were mixed by moderate vortexing. Samples were centrifuged at $5000 \mathrm{~g}$ for $5 \mathrm{~min}$ to permit phase separation and the lower organic phase was recovered. The aqueous phase was reextracted five more times and the organic phases pooled. Lipids were extracted from liver by placing the entire liver directly into $10 \mathrm{vol}-$ umes of chloroform:methanol $(2: 1, v: v)$ for $48 \mathrm{~h}$. Extracts were dried under argon, redissolved in ethanol and stored at $-20^{\circ} \mathrm{C}$ until required. Sterols were analysed by gas chromatography-mass spectrometry as described [15].

Statistics. Gene expression data is expressed as mean \pm range as described in Livak [16]. Statistical comparisons were performed using the 2-tailed Students $t$-test, with the exception of the in vivo effects of histone deacetylase inhibitors on Cyp46a1 expression. In accordance with our hypothesis that this gene is derepressed by these agents a one-tailed Student's $t$-test was used. A $P$ value of less than 0.05 was considered significant.

Ethical aspects. All animal experiments were approved by the local Animal Experimentation Ethics Committee.

\section{Results}

Derepression of CYP46A1 expression by inhibition of histone deacetylases

The mechanisms underscoring the ectopic expression of CYP46A1 have yet to be established. We investigated if CYP46A1 expression was regulated by histone acetylation status. Treatment of SH-SY5Y neuroblastoma cells with TSA, a potent inhibitor of histone deacetylation, lead to a marked time-dependent derepression of CYP46A1 expression and essentially restored the expression of CYP46A1 to that of neurons (Fig. 1A). This observation was replicated in HepG2 hepatoma cells (results not shown). To further validate these findings we also performed RT-qPCR on SH-SY5Y cells treated with $0.5 \mu \mathrm{M}$ TSA for $48 \mathrm{~h}$ and observed a highly significant 150 -fold increase in CYP46A1 expression $(P<0.00001)$ (Fig. 1B). For
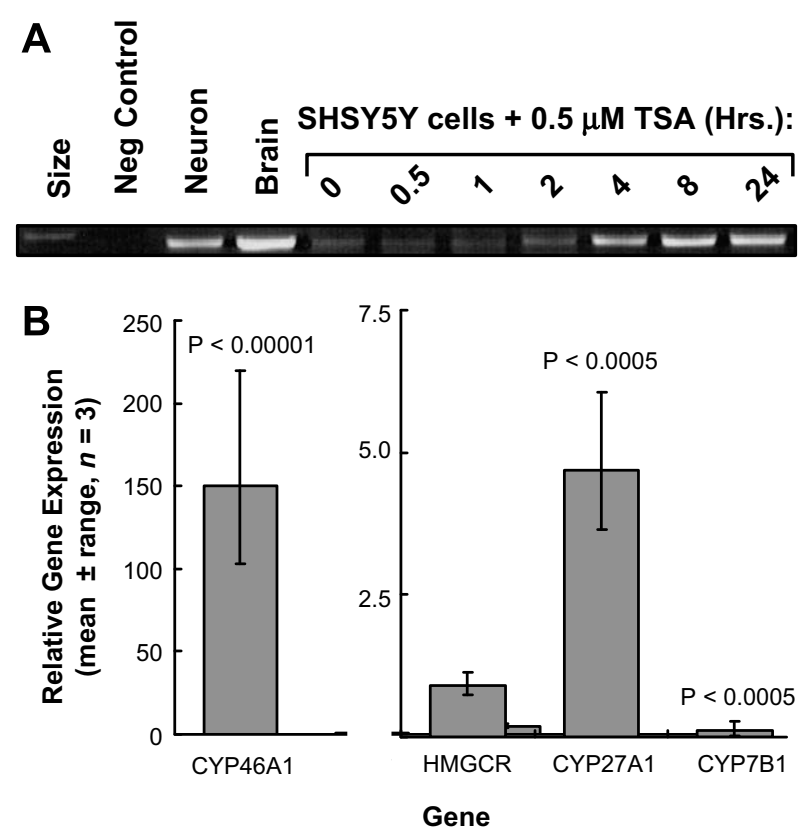

Fig. 1. Derepression of cholesterol 24-hydroxylase by histone deacetylase inhibition. (A) SH-SY5Y cells were treated with $0.5 \mu \mathrm{M}$ of trichostatin A and gene expression was evaluated by reverse transcription-PCR; (B) SH-SY5Y cells were treated with $0.5 \mu \mathrm{M}$ of trichostatin $\mathrm{A}$ for $48 \mathrm{~h}$ and gene expression was evaluated by qPCR. Data is expressed as mean \pm range. 

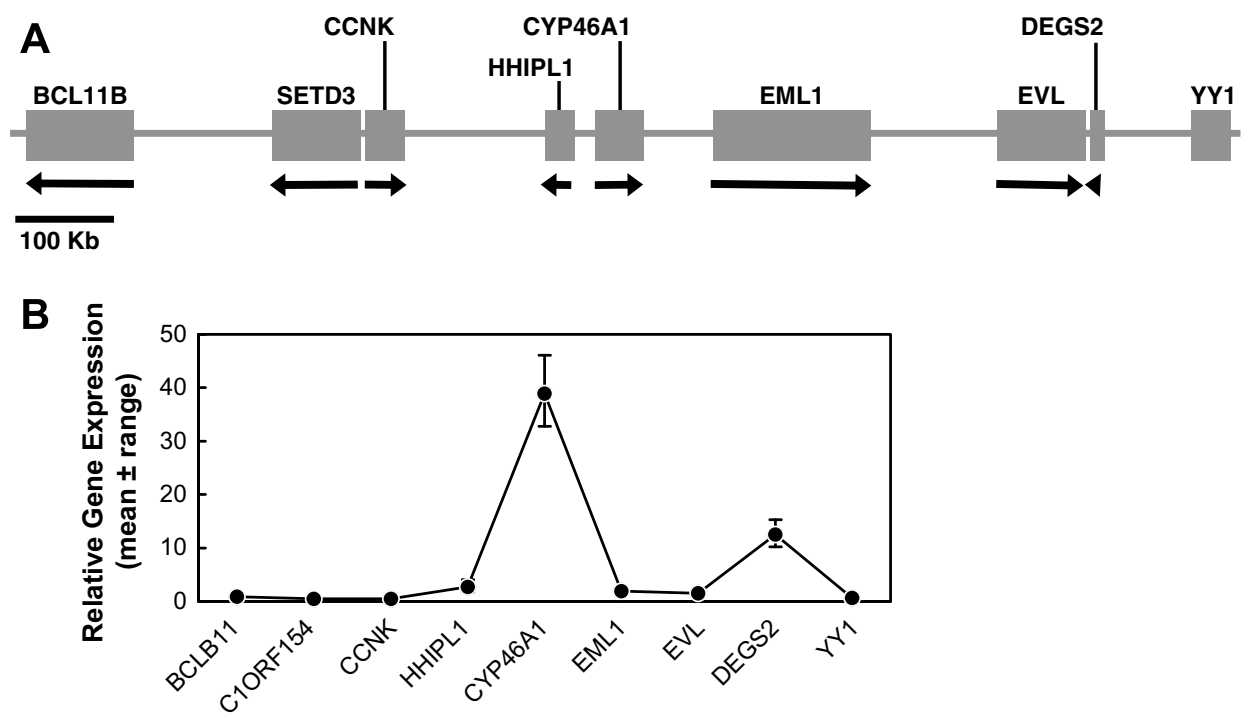

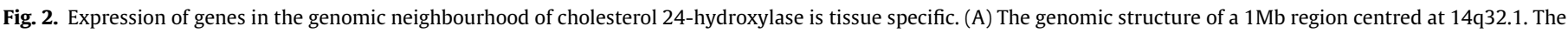

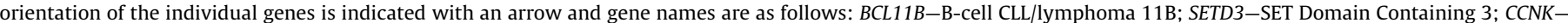

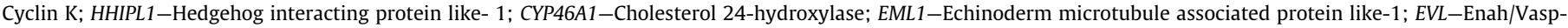

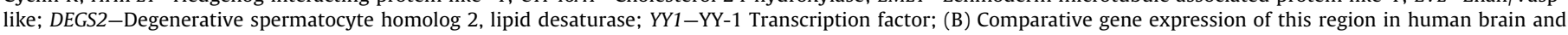
liver. Gene expression in the liver is set to unity and a larger value indicates greater expression in the brain. Data is expressed as mean \pm range.

reasons of comparison we also measured the expression levels of other genes known to be important for brain sterol homeostasis. There was no significant effect on the expression of $H M G C R$, while the expression of CYP7B1 was decreased and that of CYP27A1 increased $(P<0.0005$ for both $)$.

\section{Long-range chromatin structure at CYP46A1}

Previously published data indicated that the expression of CYP46A1 is limited to the brain, with only trace amounts present in other tissues [17]. To determine if the expression of genes in the genomic neighbourhood of CYP46A1 were also coordinated in different tissues we examined the expression of genes in a $1 \mathrm{Mb}$ region centred on CYP46A1 (see Fig. 2A). Using the brain and the liver as model organs we show that in this region, CYP46A1 and DEGS2 were expressed at greater levels in the brain than in the liver (see Fig. 2B). This data is consistent with previously presented data on these genes, as well as public gene expression datasets (e.g. the Allen Brain Atlas).

\section{Effects of valproate treatment on cholesterol homeostasis}

Given the potent effects of histone deacetylase inhibition on the mRNA levels of CYP46A1 under in vitro conditions, we considered it important to define if this finding could be replicated in vivo. Initially we used the anti-epilieptic drug valproic acid (VPA), which is well known to have histone deacetylase inhibitor activity. Intraperitoneal injection of a high dose of VPA $(700 \mathrm{mg} / \mathrm{kg}$ ) for resulted in a modest induction of the mRNA expression of $\mathrm{Hmgcr}$ and Cyp46a1 in the liver, and Cyp46a1 in the brain (see Fig. 3A). However, treatment with VPA at this level lead to the death of three of the treated mice, two at day three and one at day four indicating that any observed changes in mRNA levels may be influenced by the general toxic effects of VPA. A similar experiment with a lower dose of VPA ( $350 \mathrm{mg} / \mathrm{kg}$ body weight) led to a similar pattern of changes of mRNA with a significant increase in Hmgcr and Cyp46a1 expression $(P<0.05$ for both). There were no matching changes in hepatic or cerebral steady-state sterol levels (results not shown). To exclude the possibility that the capacity for downstream sterol metabolism (i.e. $7 \alpha$-hydroxylation 24S-hydroxycholesterol) may have been altered by VPA treatment, we measured the mRNA levels of Cyp39a1 in both the liver and brain. Surprising, we found a 2-fold increase in expression of Cyp39a1 in the brain $(P<0.01)$ and a $50 \%$ decrease in hepatic expression $(P<0.002)$ (Fig. 3B).

\section{Effects of TSA treatment on cholesterol homeostasis}

In light of the abovementioned toxic effects of high dose VPA treatment we decided to employ the potent histone deacetylase inhibitor TSA. We initially studied the dose dependent effects of TSA treatment in an acute model. IP injection of TSA to male mice resulted in dose dependent increases in the expression of brain Cyp46a1 and Cyp39a1. This was recapitulated in the liver with increases in hepatic Cyp46a1 and Cyp7b1 expression and decreases in both Hmgcr and Cyp39a1 levels (Fig. 4A). Intriguingly, the response of female mice to the same regimen was markedly different (results not shown).

We then treated animals with $2 \mathrm{mg} / \mathrm{kg}$ TSA for nine days. This resulted in a small-but-significant reduction in brain Hmgcr mRNA expression $(P<0.05)$. No significant change was observed in the cerebral expression of Cyp46a1, Cyp39a1 or Cyp7b1 (Fig. 4B). The situation in the liver was similar to that observed following VPA treatment, with a 2.5-fold increase in hepatic Cyp46a1 expression. In accordance with our hypothesis that inhibition of histone deacetylase increased the mRNA levels of Cyp46a1, this was significant following a one-tailed $t$-test $(P<0.05)$. Again, there were no measurable differences in the total brain or liver sterol levels (results not shown).

\section{Discussion}

Previously we have shown that the activation of a reporter construct containing firefly luciferase under the control of $2.6 \mathrm{~Kb}$ of the human CYP46A1 promoter was refractory to interventions known to regulate other genes involved in cholesterol balance [9]. However, several groups have independently demonstrated the presence of ectopic expression of CYP46A1. The current study was initiated to determine if epigentic mechanisms could be involved in these phenomena.

The observation that TSA treatment potently derepressed CYP46A1 expression supports our hypothesis that chromatin con- 
A

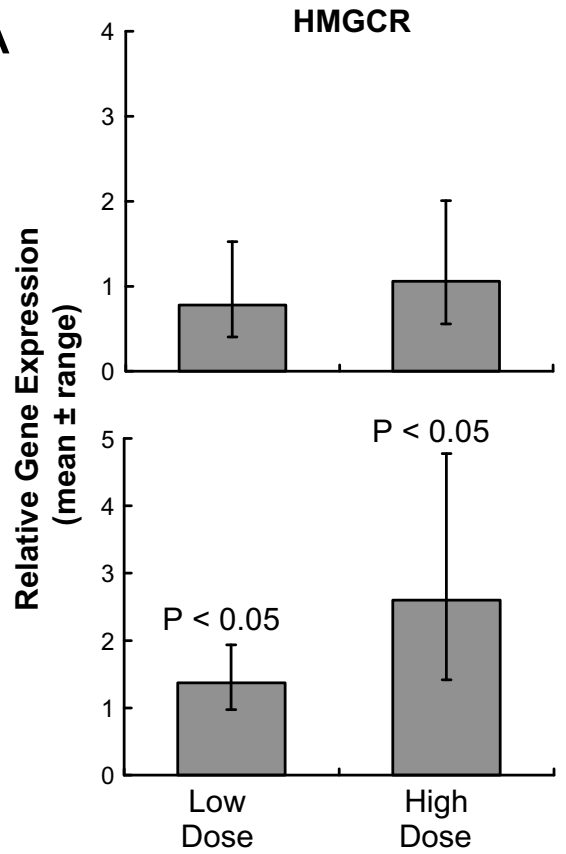

B

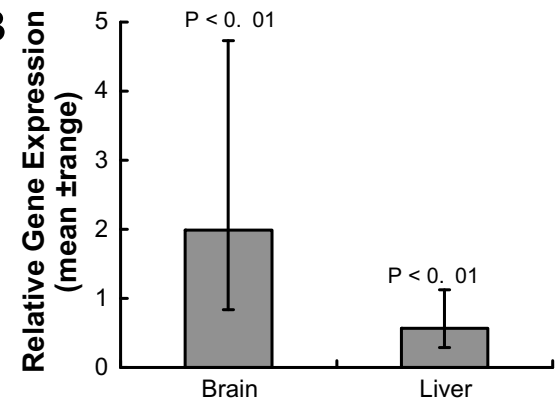

$4 \quad$ CYP46A1
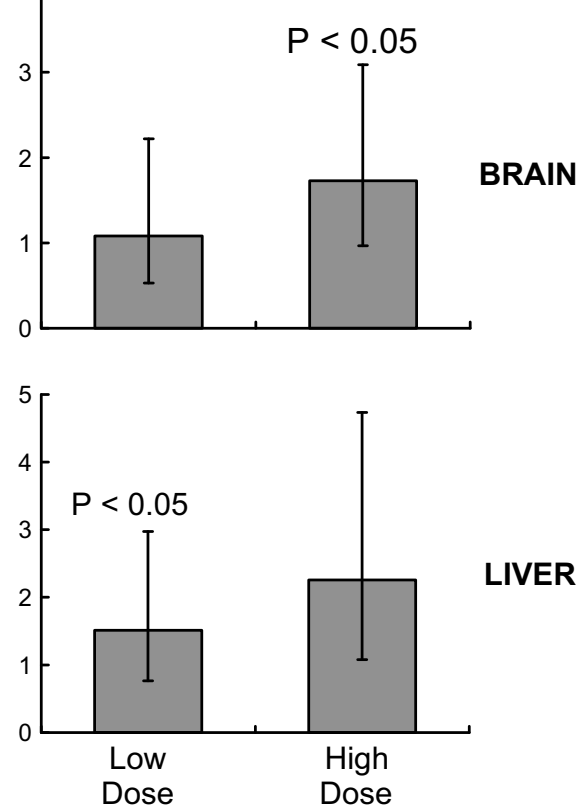

LIVER

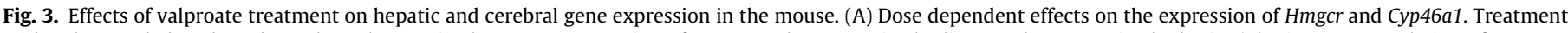

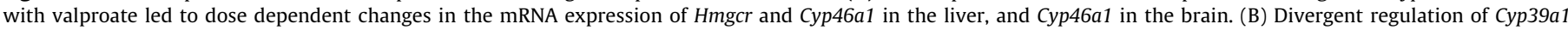

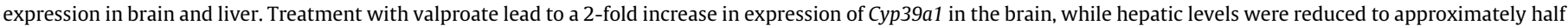
of the control value (Fig. 3b).

densation was important for the transcriptional activation of CYP46A1. Examination of the relative expression of the genes in a $1 \mathrm{Mb}$ genomic region centred on CYP46A1 revealed two areas with markedly higher expression in the brain compared with the liverCYP46A1 and DEGS2. This finding is consonant with the idea that a large genomic region is silenced in neurons. Taken together these data provide support for the hypothesis that epigenetic mechanisms are involved in establishing the neuronal expression of CYP46A1. Inspection of the CYP46A1 gene revealed two candidate sites for the neuron restrictive silencing factor (NRSF), a transcription factor known to be involved in neuron specific gene expression [18]. In pilot studies we attempted to abrogate any effects of NRSF on CYP46A1 expression using a dominant negative NRSF mutant construct. However no significant effect on CYP46A1 mRNA levels was observed (results not shown).

The overall pattern of changes in the mRNA expression of Cyp46a1 was remarkably consistent under a variety of different treatment schemes, despite the difficulties in normalising gene expression data following treatment with such a potent gene regulator [19]. A further complication is the pharmacokinetic profile of TSA-the plasma half-life of this compound in mice is 7-9 min and available data indicates significant and rapid hepatic metabolism, potentially to less active compounds [20]. The short half-life may be part of the reason for the marked differences between the acute and chronic TSA mediated regulation of selected genes e.g. cyp7b1.

An intriguing finding of our investigations into the acute effects of TSA was the finding of gender specific responses to effects of the treatment. It has been established that hepatic expression of Cyp7b1 is greater in male mice, whereas that of Cyp39a1 is greater in females $[21,22]$. This pattern appears to be potentiated by TSA treatment, at least under acute conditions, suggesting that epigenetic mechanisms may be a general regulator of sexually dimorphic cytochrome P450 expression (results not shown).

A surprising finding was the detection of significant levels of Cyp39a1 in the brain. This cytochrome P450, which is a $7 \alpha$-hydroxylase highly specific for 24S-hydroxycholesterol, was originally cloned as liver specific species [21]. Subsequent investigations have identified Cyp39a1 mRNA or protein in brain or the non-pigmented epithelium of the retina $[23,24]$. To the best of our knowledge, this is the first demonstration of pharmacological regulation of CYP39A1. At present the reason for the diametrically opposite regulation in brain and liver is unclear. However, this provides a plausible explanation for absence of changes in brain 24S-hydroxycholesterolinduction of the CYP39A1 within the brain may theoretically lead to intracerebral production of $7 \alpha, 24 \mathrm{~S}$-dihydroxycholesterol and mask any increase in 24S-hydroxycholesterol content. An analogous situation may exist for 27-hydroxycholesterol. 
A
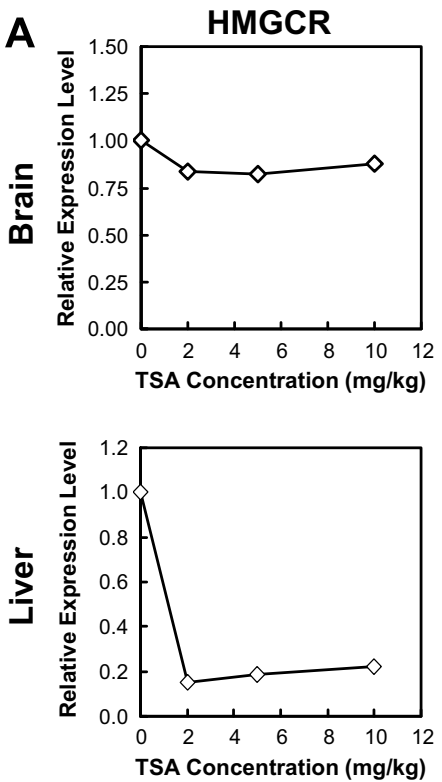

CYP46A1
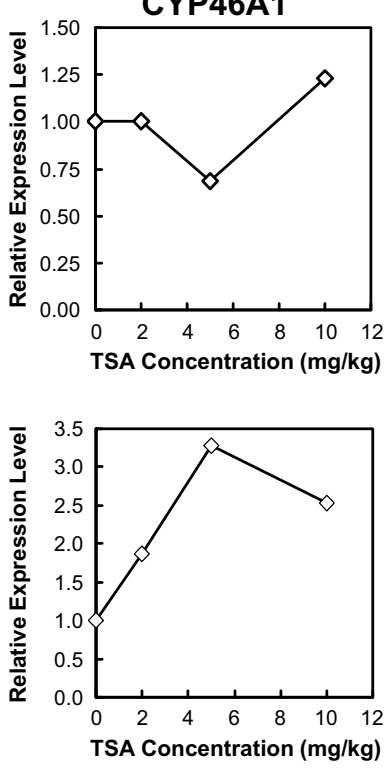

CYP7B1
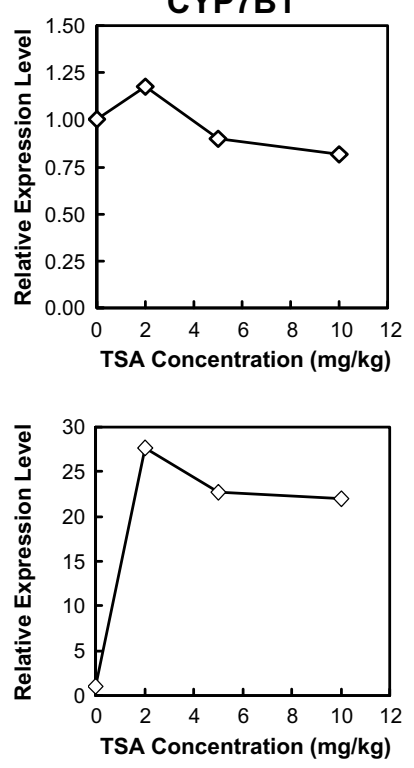

CYP39A1
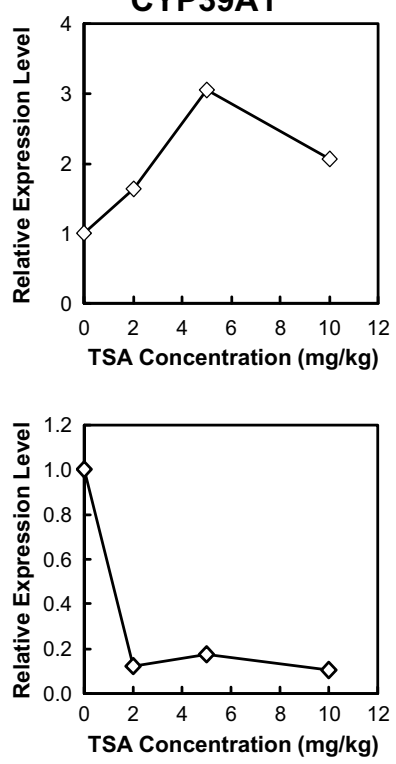

B

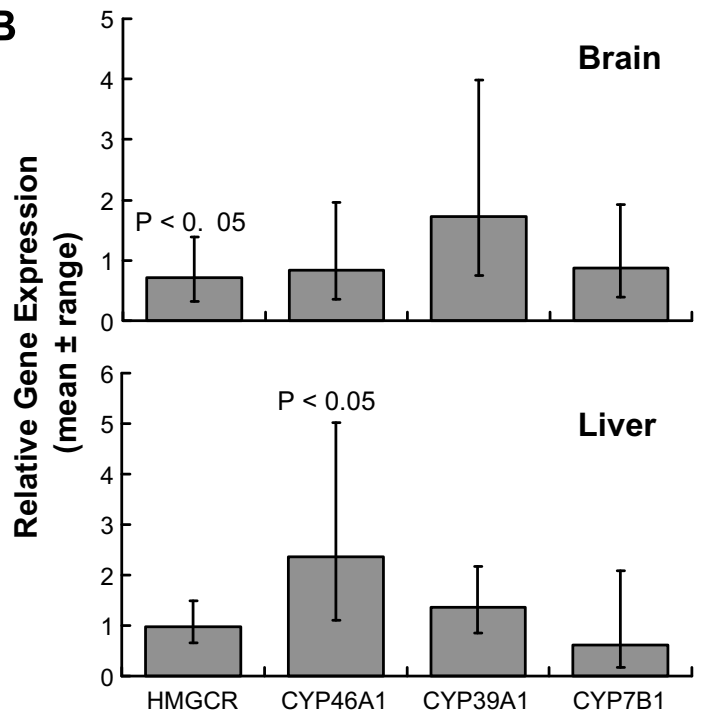

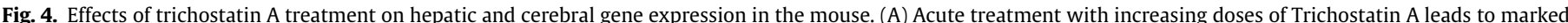

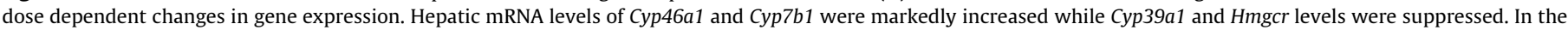

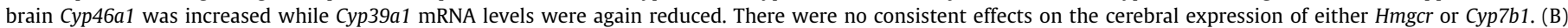

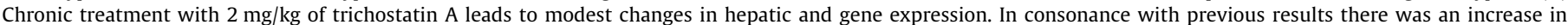

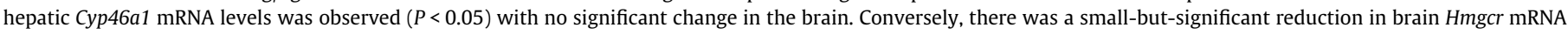
levels $(P<0.05)$ while hepatic levels were unchanged.

It has previously been shown that some genes involved in cholesterol synthesis are epigenetically regulated [25]. The current data supports the contention that epignetic mechanisms are of general importance for the regulation of the transcription of cytochrome P450s involved in metabolism and elimination of cholesterol via oxidative mechanisms.

\section{Acknowledgments}

The research undertaken was supported by the Swedish Brain Foundation, Swedish Brain Power, the Thurings Foundation, the Stohnes Foundation, the Karolinska Institutet Research Fund, and the Swedish Science Council. The initial part of this study was performed with support from Pfizer. We would also like to thank Dr. Elena Feinstein for useful discussions.

\section{References}

[1] J.M. Dietschy, S.D. Turley, Thematic review series: brain lipids, cholesterol metabolism in the central nervous system during early development and in the mature animal, J. Lipid Res. 45 (2004) 1375-1397.

[2] J.M. Dietschy, S.D. Turley, D.K. Spady, Role of liver in the maintenance of cholesterol and low density lipoprotein homeostasis in different animal species, including humans, J. Lipid Res. 34 (1993) 1637-1659.

[3] S. Meaney, D. Lütjohann, U. Diczfalusy, I. Björkhem, Formation of oxysterols from different pools of cholesterol as studied by stable isotope technique: cerebral origin of most circulating 24S-hydroxycholesterol in rats, but not in mice, Biochim. Biophys. Acta 1486 (2000) 293-298.

[4] S. Meaney, M. Hassan, A. Sakinis, D. Lütjohann, K. von Bergmann, A Wennmalm, U. Diczfalusy, I. Björkhem, Evidence that the major oxysterols in human circulation originate from distinct pools of cholesterol: a stable isotope study, J. Lipid Res. 42 (2001) 70-78.

[5] I. Björkhem, S. Meaney, Brain cholesterol: long secret life behind a barrier, Arterioscler. Thromb. Vasc. Biol. 24 (2004) 806-815. 
[6] I. Björkhem, D. Lütjohann, O. Breuer, A. Sakinis, A. Wennmalm, Importance of a novel oxidative mechanism for elimination of brain cholesterol. Turnover of cholesterol and 24(S)-hydroxycholesterol in rat brain as measured with ${ }^{18} \mathrm{O}_{2}$ techniques in vivo and in vitro, J. Biol. Chem. 272 (1997) 30178-30184.

[7] C. Xie, E.G. Lund, S.D. Turley, D.W. Russell, J.M. Dietschy, Quantitation of two pathways for cholesterol excretion from the brain in normal mice and mice with neurodegeneration, J. Lipid Res. 44 (2003) 1780-1789.

[8] E.G. Lund, C. Xie, T. Kotti, S.D. Turley, J.M. Dietschy, D.W. Russell, Knockout of the cholesterol 24-hydroxylase gene in mice reveals a brain-specific mechanism of cholesterol turnover, J. Biol. Chem. 278 (2003) 22980-22988.

[9] Y. Ohyama, S. Meaney, M. Heverin, L. Ekström, A. Brafman, M. Shafir, U. Andersson, M. Olin, G. Eggertsen, U. Diczfalusy, E. Feinstein, I. Björkhem, Studies on the transcriptional regulation of cholesterol 24-hydroxylase (CYP46A1): marked insensitivity toward different regulatory axes, J. Biol. Chem. 281 (2006) 3810-3820.

[10] C.E. Teunissen, S. Floris, M. Sonke, C.D. Dijkstra, H.E. De Vries, D. Lütjohann, 24Shydroxycholesterol in relation to disease manifestations of acute experimental autoimmune encephalomyelitis, J. Neurosci. Res. 85 (2007) 1499-1505.

[11] C.M. Cartagena, F. Ahmed, M.P. Burns, A. Pajoohesh-Ganji, D.T. Pak, A.I. Faden, G.W. Rebeck, Cortical injury increases cholesterol 24S hydroxylase (Cyp46) levels in the rat brain, J. Neurotrauma 25 (2008) 1087-1098.

[12] N. Bogdanovic, L. Bretillon, E.G. Lund, U. Diczfalusy, L. Lannfelt, B. Winblad, D.W. Russell, I. Björkhem, On the turnover of brain cholesterol in patients with Alzheimer's disease. Abnormal induction of the cholesterol-catabolic enzyme CYP46 in glial cells, Neurosci. Lett. 314 (2001) 45-48.

[13] I. Milagre, M.J. Nunes, M.J. Gama, R.F. Silva, J.M. Pascussi, M.C. Lechner, E. Rodrigues, Transcriptional regulation of the human CYP46A1 brain-specific expression by Sp transcription factors, J. Neurochem. 106 (2008) 835-849.

[14] S.H. Leuba, J. Zlatanova, Chromatin Structure and Dynamics: State-of-the-Art, Elsevier, 2004

[15] M. Heverin, N. Bogdanovic, D. Lütjohann, T. Bayer, I. Pikuleva, L. Bretillon, U. Diczfalusy, B. Winblad, I. Björkhem, Changes in the levels of cerebral and extracerebral sterols in the brain of patients with Alzheimer's disease, J. Lipid Res. 45 (2004) 186-193.
[16] K.J. Livak, T.D. Schmittgen, Analysis of relative gene expression data using realtime quantitative PCR and the 2(-Delta Delta C(T)) Method, Methods 25 (2001) 402-408.

[17] E.G. Lund, J.M. Guileyardo, D.W. Russell, CDNA cloning of cholesterol 24hydroxylase, a mediator of cholesterol homeostasis in the brain, Proc. Natl. Acad. Sci. USA 96 (1999) 7238-7243.

[18] N. Ballas, G. Mandel, The many faces of REST oversee epigenetic programming of neuronal genes, Curr. Opin. Neurobiol. 15 (2005) 500-506.

[19] A. Mogal, S.A. Abdulkadir, Effects of Histone Deacetylase Inhibitor (HDACi) Trichostatin-A (TSA) on the expression of housekeeping genes, Mol. Cell. Probes 20 (2006) 81-86.

20] L. Sanderson, G.W. Taylor, E.O. Aboagye, J.P. Alao, J.R. Latigo, R.C. Coombes, D.M. Vigushin, Plasma pharmacokinetics and metabolism of the histone deacetylase inhibitor trichostatin a after intraperitoneal administration to mice, Drug Metab. Dispos. 32 (2004) 1132-1138.

[21] J. Li-Hawkins, E.G. Lund, A.D. Bronson, D.W. Russell, Expression cloning of an oxysterol $7 \alpha$-hydroxylase selective for 24 -hydroxycholesterol, J. Biol. Chem. 275 (2000) 16543-16549.

22] H. Uppal, S.P. Saini, A. Moschetta, Y. Mu, J. Zhou, H. Gong Y. Zhai, S. Ren, G.K. Michalopoulos, D.J. Mangelsdorf, W. Xie, Activation of LXRs prevents bile acid toxicity and cholestasis in female mice, Hepatology 45 (2007) 422432.

[23] H. Ikeda, M. Ueda, M. Ikeda, H. Kobayashi, Y. Honda, Oxysterol $7 \alpha$-hydroxylase (CYP39A1) in the ciliary nonpigmented epithelium of bovine eye, Lab. Invest 83 (2003) 349-355.

24] S. Steckelbroeck, M. Watzka, D. Lutjohann, P. Makiola, A Nassen, V.H. Hans, H. Clusmann, A. Reissinger, M. Ludwig, L. Siekmann, D. Klingmuller, Characterization of the dehydroepiandrosterone (DHEA) metabolism via oxysterol $7 \alpha$-hydroxylase and 17-ketosteroid reductase activity in the human brain, J. Neurochem. 83 (2002) 713-726.

[25] A. Villagra, N. Ulloa, X. Zhang, Z. Yuan, E. Sotomayor, E. Seto, Histone deacetylase 3 down-regulates cholesterol synthesis through repression of lanosterol synthase gene expression, J. Biol. Chem. 282 (2007) 3545735470. 